\title{
Rancang Bangun Aplikasi Pendeteksi Suara Tangisan Bayi
}

\author{
Welly Setiawan Limantoro, Chastine Fatichah, dan Umi Laili Yuhana \\ Jurusan Teknik Informatika, Fakultas Teknologi Informasi, Institut Teknologi Sepuluh Nopember (ITS) \\ Jl. Arief Rahman Hakim, Surabaya 60111 Indonesia \\ e-mail: chastine@if.its.ac.id
}

\begin{abstract}
Abstrak-Suara tangisan bayi merupakan sebuah tanda dari bayi yang mengalami suatu masalah. Namun, tidak semua orang dapat mengenali arti tangis bayi. Beberapa penelitian tentang deteksi suara tangis bayi sudah dilakukan oleh beberapa peneliti, namun saat ini masih belum ada penelitian yang membuat sebuah aplikasi pendeteksi suara tangis bayi berbasis web. Pada penelitian ini, sebuah aplikasi dibuat untuk membantu pengguna mengenali suara tangis bayi berbasis Dunstan Baby Language. Metode yang diterapkan pada aplikasi ini adalah ekstraksi fitur suara tangis bayi dengan algoritma Mel-Frequency Cepstrum Coefficient (MFCC), normalisasi hasil ekstraksi fitur, dan klasifikasi $K$ nearest Neighbor. Dari berbagai pengujian yang dilakukan, dapat disimpulkan bahwa akurasi rata-rata terbaik sebesar $\mathbf{7 5 , 9 5 \%}$ dapat dicapai ketika menggunakan parameter wintime pada ekstraksi fitur MFCC sebesar 0,08 detik, proporsi data latih $85 \%$ dan data uji $15 \%$ dari setiap kelas, normalisasi ekstraksi fitur dengan Standard Deviation Normalization, dan klasifikasi $K$ nearest Neighbor dengan $k=1$. Hasil ini lebih baik jika dibandingkan dengan metode klasifikasi lain seperti Naive Bayes, Neural Network, maupun Support Vector Machine. Pada pengujian aplikasi dengan seluruh data, akurasi rata-rata yang sebesar 96,57\% dapat dicapai ketika menggunakan parameter wintime pada ekstraksi fitur MFCC sebesar 0,08 detik, proporsi data latih $\mathbf{8 5 \%}$ setiap kelas, normalisasi ekstraksi fitur dengan Standard Deviation Normalization, dan klasifikasi K-nearest Neighbor dengan $k=1$.
\end{abstract}

Kata Kunci-Dunstan Baby Language, K-nearest Neighbor, MelFrequency Cepstrum Coefficient, Suara Tangis Bayi

\section{PENDAHULUAN}

S UARA tangisan bayi merupakan sebuah tanda dari bayi yang mengalami suatu masalah. Suara tangisan tersebut dapat digunakan untuk mengidentifikasi masalah pada bayi, seperti kelaparan, kesakitan, rasa kantuk, rasa tidak nyaman, kedingingan atau kepanasan, dan lain-lain. Dari suara tangis itu, seseorang yang telah terbiasa mengasuh bayi dapat mengerti apa maksud tangisan tersebut. Namun, tidak semua orang mengerti arti tangis bayi.

Dari permasalahan tentang tangis bayi, ada beberapa penelitian yang mengangkat tema bagaimana cara untuk mendeteksi masalah pada tangis bayi. Beberapa penelitian tersebut ialah "Application of Neuro-Fuzy Approaches to Recognition and Classification of Infant Cry" [1], "Identifikasi Arti Tangis Bayi Versi Dunstan Baby Language Menggunakan Jarak Terpendek dari Jarak Mahalanobis" [2], dan "Normal and Hypoacoustic Infant Cry Signal Classification Using TimeFrequency Analysis and General Regression Neural Network" [3]. Penelitian [1] dan [2] menggunakan Dunstan Baby Language sebagai acuan untuk mengidentifikasi jenis tangis bayi, sementara penelitian [3] fokus pada identifikasi suara tangis bayi yang normal atau tuli. Berdasarkan tiga penelitian tersebut, dapat disimpulkan bahwa penelitian tentang arti tangis bayi terus berkembang, baik dari segi metode ekstraksi fitur maupun metode identifikasi. Namun, saat ini masih belum ada penelitian yang mengembangkan aplikasi pendeteksi tangis bayi berbasis web agar dapat digunakan oleh banyak orang untuk mengetahui arti suara tangis bayi.

Maka dari itu, untuk mengenal arti tangis bayi berbasis Dunstan Baby Language, penulis menerapkan metode ekstraksi fitur Mel-Frequency Cepstrum Coefficients (MFCC) dan metode klasifikasi $K$-nearest Neighbor pada aplikasi pendeteksi suara tangisan bayi berbasis web. Metode ekstraksi fitur MFCC dipilih karena telah digunakan oleh banyak peneliti untuk menganalisa pola kecocokan suara, sedangkan metode klasifikasi K-nearest Neighbor dipilih karena waktu yang diperlukan untuk komputasi klasifikasi pada data uji yang cukup singkat dengan komposisi data latih yang cukup banyak. Pembuatan aplikasi berbasis web ini dipilih karena mempertimbangkan kemudahan penggunaan aplikasi di manapun dan kapanpun. Selain itu, pengguna tidak perlu mengalokasikan ruang pada media penyimpanan untuk pemasangan aplikasi, baik pada komputer atau perangkat bergerak lainnya, seperti smartphone atau tablet. Dengan adanya aplikasi tersebut, pengguna diharapkan dapat mengetahui arti dari suara tangisan bayi yang bersangkutan sehingga dapat memberikan penanganan yang tepat terhadap suara tangisan tersebut.

\section{TINJAUAN PUSTAKA}

\section{A. Dunstan Baby Language}

Dunstan Baby Language [4] adalah gagasan tentang arti tangisan bayi yang dicetuskan oleh Priclilla Dunstan pada tahun 2006. Menurut Pricilla, terdapat 5 jenis tangisan bayi universal (berlaku pada seluruh bayi di dunia) yang memiliki arti masingmasing, yaitu:

- Neh (Aku lapar) - Seorang bayi menggunakan refleks suara "Neh" untuk berkomunikasi bahwa ia sedang kelaparan. Suara yang dihasilkan berasal dari refleks menghisap dan lidah didorong di atap mulut.

- Owh (Aku mengantuk) - Seorang bayi menggunakan refleks suara "Owh" untuk berkomunikasi bahwa ia lelah. Suara yang dihasilkan terdegar seperti orang yang sedang menguap.

- Heh (Aku merasa tidak nyaman) - Seorang bayi 
menggunakan refleks suara "Heh" untuk berkomunikasi bahwa ia merasa tertekan, tidak nyaman, atau membutuhkan popok baru. Suara yang dihasilkan ialah respon pada masalah kulit bayi, biasanya rasa kepanasan (disertai keringat) atau rasa gatal.

- Eairh (Ada angin di perutku) - Seorang bayi menggunakan refleks suara "Eairh" untuk berkomunikasi bahwa ia ingin buang angin atau masalah perut. Suara tersebut dihasilkan ketika bayi tak dapat bersendawa, kemudian angin tersebut masuk ke perut dan menekan otot-otot perut agar angin tersebut dapat dikeluarkan. Seringkali, suara ini juga mengindikasaikan bayi ingin buang air besar yang disertai dengan gerakan menekuk lutut ke tubuhnya.

- Eh (Aku ingin bersendawa) - Seorang bayi menggunakan suara refleks "Eh" untuk berkomunikasi bahwa ia ingin bersendawa. Suara tersebut dihasilkan ketika angin tidak dapat keluar dan terperangkap di sekitar dada dan disertai dengan refleks untuk mengeluarkan angin tersebut melalui mulut.

\section{B. Mel-Frequency Cepstrum Coefficient}

Mel-Frequency Cepstral Coefficients (MFCC) [5] adalah sebuah metode ekstraksi fitur suara yang merubah sinyal suara menjadi vektor. Keunggulan dari MFCC ialah sebagai berikut:

- Dapat menangkap karakter suara untuk mengetauhi pola pada suara tertentu.

- Memberikan output berupa vektor dengan ukuran data yang kecil namun tidak menghilangkan karakteristik dari suara yang diekstrak.

- Cara kerja algoritma MFCC mirip dengan cara kerja pendengaran manusia dalam memberikan persepsi terhadap suara yang didengarkan.

Alur ekstraksi fitur MFCC terdapat pada Gambar 1.

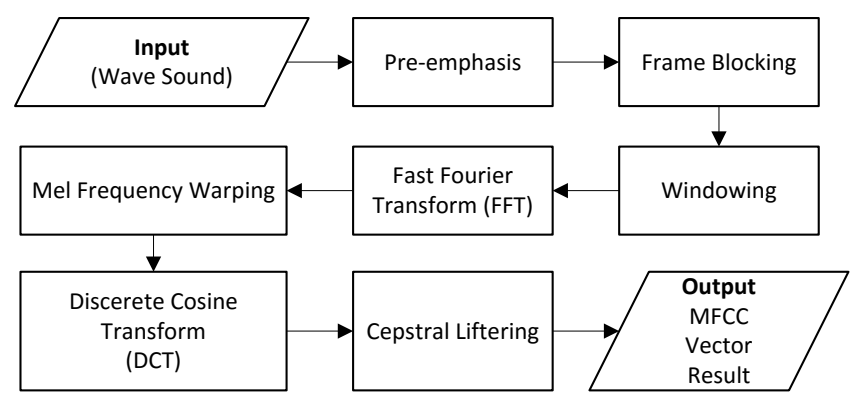

Gambar 1 Diagram Alur Ekstraksi Fitur MFCC

\section{1) Pre-Emphasis}

Pre-Emphasis [6] digunakan untuk mempertahankan frekuensi-frekuensi tinggi pada sebuah spektrum yang umumnya tereduksi saat proses produksi suara. Pada tahap ini, file audio yang telah dibaca sebagai data sinyal frekuensi dalam tipe data array sepanjang $N$ detik akan ditransformasi menjadi sinyal frekuensi baru dengan persamaan (1) [7]. Persamaan Pre-Emphasis tertulis pada persamaan (1), di mana $y_{n}$ adalah sinyal hasil Pre-Emphasis dan $x_{n}$ adalah sinyal sebelum PreEmphasis. Misalkan nilai dari $\alpha=0,97$, maka 97\% dari setiap sampel dianggap berasal dari sampel sebelumnya.

$$
y_{n}=x_{n}-\alpha \times x_{n-1}, 0.9 \leq \alpha \leq 1.0
$$

\section{2) Frame Blocking}

Frame Blocking [6] digunakan untuk membuat segmentasi pada sinyal frekuensi sebesar 20-30 milidetik (dikenal sebagai frame). Sinyal suara dibagi menjadi $N$ sampel frame dan frame yang berdekatan dipisahkan oleh $M(M<N)$ [5]. Pada umumnya nilai $N=256$ dan $M=100$. Panjang frame akan menentukan keberhasilan analisa spektral. Ukuran frame harus sepanjang mungkin untuk menunjukkan resolusi frekuensi yang baik, namun juga harus cukup pendek untuk menunjukkan resolusi waktu yang baik [6].

Proses frame blocking ini akan dilakukan secara terusmenerus sampai seluruh sinyal dapat diproses. Pada umumnya, proses ini dilakukan secara overlapping pada setiap frame-nya. Panjangnya overlap yang umum digunakan ialah $30 \%$ hingga $50 \%$ dari panjang frame. Dengan adanya overlapping, hilangnya karakteristik suara pada perbatasan perpotongan setiap frame dapat dihindari.

Sebagai contoh, jika audio yang telah melewati proses PreEmphasis memiliki sample rate sebesar $16000 \mathrm{~Hz}$, maka segmentasi selama 20 milidetik dilakukan setiap 320 frame. Hasil tersebut diperoleh dari perkalian sample rate dengan durasi segmentasi. Kemudian, jika overlap yang dilakukan sebesar 50\%, maka segmen pertama ialah dengan frame urutan 1-320, diikuti dengan segmen kedua dengan frame urutan 160480 dan seterusnya [7].

\section{3) Windowing}

Windowing [6] digunakan untuk mengurangi terjadinya efek aliasing pada sinyal yang diproses setelah proses framing. Aliasing adalah sinyal baru yang frekuensinya berbeda dengan frekuensi sinyal aslinya akibat dari rendahnya sampling rate atau proses frame blocking yang menyebabkan sinyal terputus. Pada tahap ini, setiap sinyal frekuensi berupa spektrum suara ke- $n$ yang telah diproses dari Frame Blocking dikalikan dengan nilai Hamming Window [7]. Nilai Hamming Window didapat dari fungsi window. Persamaan windowing tertulis pada (2), di mana $N$ adalah jumlah sampel pada setiap frame, $y_{n}$ adalah nilai sampel sinyal hasil windowing, $x_{n}$ adalah nilai sampel dari frame sinyal ke- $n$, dan $w_{n}$ adalah fungsi window. Fungsi window yang sering digunakan pada proses windowing ini ialah Hamming Window (3) karena menghasilkan sidelobe level yang tidak terlalu tinggi dan noise yang tidak terlalu banyak.

$$
\begin{gathered}
y_{n}=x_{n} \times w_{n}, 0 \leq n \leq N-1 \\
w_{n}=0.54-0.46 \cos \frac{2 \pi n}{N-1}, 0 \leq n \leq N-1
\end{gathered}
$$

\section{4) Fast Fourier Transform}

Fast Fourier Transform [6] (FFT) digunakan mengubah tiap frame frekuensi pada sample $N$ dari domain waktu menjadi domain frekuensi dan untuk menganalisa spectral properties berdasarkan sinyal yang dimasukkan. Spectral properties ini biasa dikenal sebagai spectogram. Spectogram berhubungan dengan waktu dan frekuensi. Jika resolusi waktu yang digunakan tinggi, maka frekuensi yang dihasilkan menjadi semakin rendah. Pada tahap ini, sinyal frekuensi dari proses windowing akan diproses dengan persamaan (4), di mana $X_{k}$ adalah jumlah frekuensi $k$ pada sinyal, $k$ adalah frekuensi audio sebelum FFT ( $0 \mathrm{~Hz}$ sampai $N-1 \mathrm{~Hz}), x_{n}$ adalah nilai sinyal pada waktu ke- $n$, dan $N$ adalah jumlah waktu pada sampel [8]. 


$$
X_{k}=\sum_{n=0}^{N-1} x_{n} \times e^{\frac{-2 \pi k n}{N}}, n=0 \leq n \leq N-1
$$

\section{5) Mel Frequency Warping}

Mel Frequency Warping [7] dilakukan untuk menghasilkan magnitude spectrum yang bagus dan memperkecil ukuran fitur terkait. Mel Frequency Warping dilakukan dengan menerapkan filterbank untuk mengetahui ukuran energi frequency band tertentu dalam sinyal suara [6]. Filterbank ini dapat diterapkan pada domain frekuensi maupun domain waktu, namun karena digunakan untuk MFCC, maka domain frekuensi yang diterapkan pada penelitian ini.

Pada tahap Mel Frequency Warping, sinyal frekuensi yang telah diproses pada tahap Fast Fourier Transform akan dirubah ke dalam frekuensi $\mathrm{Mel}$ dengan persamaan (5), di mana $f$ adalah frekuensi sinyal. Kemudian, untuk mengetahui besarnya energi pada frekuensi $\mathrm{Mel}$, dilakukan perhitungan filterbank [7]. Persamaan filterbank terdapat pada (6), di mana $N$ adalah jumlah magnitude spektrum (nilai yang sering digunakan ialah 40), $S[j]$ adalah magnitude spectrum yang pada frekuensi $j$, $H_{i}[j]$ adalah koefisien filterbank pada frekuensi $j$, dan $M$ adalah jumlah channel pada filterbank.

$$
\begin{gathered}
\operatorname{Mel}(f)=2595 \log _{10}\left(1+\frac{f}{700}\right) \\
y[i]=\sum_{i=1}^{N} S[j] H_{i}[j], j=1 \leq i \leq M
\end{gathered}
$$

\section{6) Discrete Cosine Transform}

Discrete Cosine Transform [7] merupakan proses terakhir dari rangkaian proses MFCC yang digunakan untuk mengonversi mel spectrum menjadi domain yang mirip waktu (dikenal sebagai quefrency) sehingga spektral lokal dapat terepresentasi dengan baik. Hasil dari konversi ini disebut sebagai Mel-Frequency Cepstrum Coefficient yang berbentuk deretan vektor akustik. Pada tahap ini, frekuensi $\mathrm{Mel}$ ditransformasi dengan persamaan (7), di mana $N$ adalah jumlah dari Mel Frequency Warping (nilai yang sering digunakan ialah 40), $L$ adalah jumlah dari Mel-Scale Cepstral Coefficients (nilai yang sering digunakan ialah 12).

$$
C_{m}=\sum_{k=1}^{N} \cos \left[m\left(k-\frac{1}{2}\right) \frac{\pi}{N}\right] E_{k}, m=1,2, \ldots, L
$$

\section{7) Cepstral Liftering}

Cepstral Liftering [9] digunakan untuk memperhalus hasil dari seluruh proses MFCC agar lebih hasilnya lebih baik saat digunakan pada pattern matching. Cepstral Liftering diimplementasikan pada hasil Discrete Cosine Transform berupa cepstral features dengan menggunakan fungsi window pada persamaan, di mana $L$ adalah jumlah cepstral coefficients dan $n$ adalah indeks dari cepstral coefficients.

$$
w_{n}=1+\frac{L}{2} \sin \left[\frac{\pi n}{L}\right]
$$

\section{Normalisasi}

Normalisasi adalah sebuah teknik penskalaan data agar distribusi data sesuai dengan standar tertentu. Beberapa teknik normalisasi yang digunakan dalam penelitian ini ialah sebagai berikut.

\section{1) Standard Deviation Normalization}

Standard Deviation Normalization [1] (9) adalah metode untuk menormalkan data berdasarkan besarnya nilai standar deviasi dari sebuah kumpulan data. Cara kerja metode ini ialah nilai data yang ke sekian dikurangi dengan nilai rata-rata dari kumpulan data terkait kemudian dibagi dengan nilai standar deviasi dari data terkait.

$$
x_{i}=\frac{\text { data }_{i}-\mu(\text { data })}{\sigma(\text { data })}
$$

\section{2) Min-Max Normalization}

Min-Max Normalization [1] (10) adalah metode untuk menormalkan data berdasarkan besarnya nilai maksimum dikurangi dengan nilai minimum dari sebuah kumpulan data. Cara kerja metode ini ialah nilai data yang ke sekian dikurangi dengan nilai minimum dari kumpulan data terkait kemudian dibagi dengan nilai maksimum yang dikurangi nilai minimum dari data terkait.

$$
x_{i}=\frac{\text { data }_{i}-\min (\text { data })}{\max (\text { data })-\min (\text { data })}
$$

\section{3) Decimal Normalization}

Decimal Normalization [1] (11) adalah metode untuk menormalkan data berdasarkan besarnya nilai $10^{j}$ ( $j$ adalah bilangan bulat). Cara kerja metode ini ialah data nilai data yang ke sekian dibagi dengan $10^{j}$.

$$
x_{i}=\frac{\operatorname{data}_{i}}{10^{j}}
$$

\section{K-nearest Neighbor}

$$
d_{E}=\sqrt{\sum_{i=1}^{n}\left(x_{i}-y_{i}\right)^{2}}
$$

K-Nearest Neighbor (KNN) [10] (12) adalah algoritma sederhana yang menyimpan semua kasus yang tersedia dan mengklasifikasikan kasus baru berdasarkan ukuran kesamaan menggunakan fungsi jarak. Cara kerja algoritma ini ialah sebuah data uji diklasifikasikan menjadi suatu kelas tertentu berdasarkan jumlah tetangga terdekat dengan menggunakan perhitungan jarak Euclidian. Saat perhitungan, jarak antar data uji dengan seluruh data latih beserta label kelas disimpan pada vektor, kemudian diurutkan berdasarkan jarak terpendek. Data uji akan masuk ke kelas tertentu berdasarkan jumlah label terbanyak dari nilai $k$ yang ditentukan. 


\section{PERANCANGAN SISTEM}
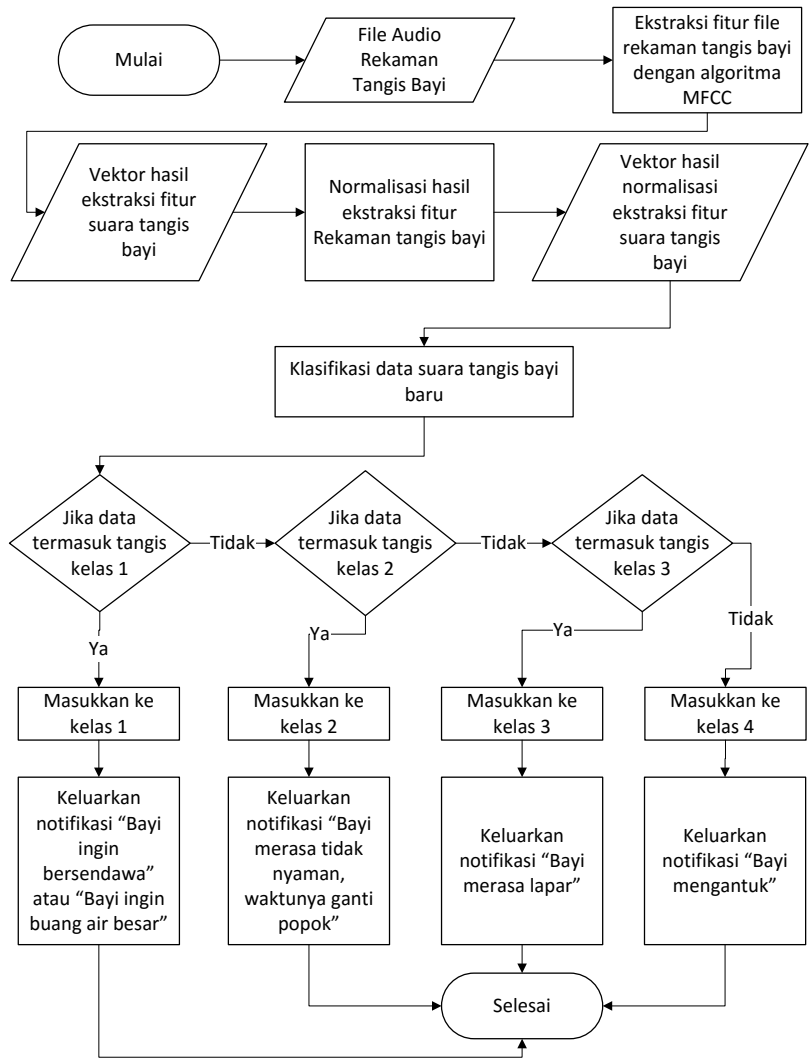

Gambar 2 Diagram Proses Klasifikasi Suara Tangis Bayi

Pada penelitian ini akan dibangun suatu sistem yang dapat melakukan klasifikasi terhadap rekaman suara tangis bayi kedalam empat kelas yaitu kelas "Eairh/Eh" (bayi ingin bersendawa, kentut, atau buang air besar), kelas "Heh" (bayi merasa tidak nyawan, waktunya ganti popok), kelas "Neh" (bayi merasa lapar), atau kelas "Owh" (bayi mulai mengantuk), di mana rekaman suara tangis bayi yang dipakai memiliki durasi maksimal 10 detik. Pada tahap ini dilakukan beberapa proses meliputi ekstraksi fitur dengan algoritma MFCC, normalisasi hasil ekstraksi fitur, dan tahap klasifikasi berdasarkan fitur yang telah didapatkan. Diagram alur klasifikasi suara tangis bayi dapat dilihat pada Gambar 2.

\section{UJI COBA DAN EVALUASI}

\section{A. Data Uji Coba}

Tabel 1

Jumlah Data Tiap Jenis Tangis Bayi

\begin{tabular}{ccc}
\hline Jenis Tangis & Kelas (angka) & Jumlah rekaman \\
\hline Eairh/Eh & 1 & 46 \\
Heh & 2 & 23 \\
Neh & 3 & 35 \\
Owh & 4 & 35 \\
\hline \hline
\end{tabular}

Data uji coba yang digunakan pada penelitian ini adalah rekaman suara tangis bayi yang didapatkan dari video tangis bayi Dunstan Baby Language yang telah dipotong-potong berdasarkan durasi waktu tertentu (maksimal 10 detik) dan dikonversi menjadi file audio dengan format ".wav", channel audio mono, dan sample rate $11205 \mathrm{~Hz}$ dengan bantuan tools Adobe Premiere Pro CS6. Video tersebut didapatkan dari penelitian [1] yang terdiri atas lima jenis tangis bayi ("Eairh", "Eh", "Heh", "Neh", dan "Owh") yang nantinya akan dikelompokkan menjadi empat kelas yaitu kelas 1 "Eairh/Eh" (bayi ingin bersendawa, kentut, atau buang air besar), kelas 2 "Heh" (bayi merasa tidak nyawan, waktunya ganti popok), kelas 3 "Neh" (bayi merasa lapar), dan kelas 4 "Owh" (bayi mulai mengantuk). Hasil potongan video berupa file audio disempurnakan dengan menghilangkan gelombang audio di bagian awal yang bernilai nol menggunakan tools Adobe Audition CS5.5. Jumlah data tiap jenis tangis bayi terdapat pada Tabel 1.

\section{B. Uji Coba Pemilihan Metode}

Uji coba dilakukan dengan mengklasifikasi data tangis bayi dari video Dunstan Baby Language yang dikonversi menjadi audio berformat ".wav" hasil ekstraksi fitur yang sudah dinormalisasi pada empat jenis tangis bayi. Hasil dari ekstraksi fitur yang sudah dinormalisasi adalah sebuah data frame dataset yang kemudian diklasifikasi dengan $K$-nearest Neighbor untuk menentukan akurasi pada masing-masing kelas. Terdapat 15 macam skenario dari uji coba dengan menggunakan kombinasi beberapa parameter. Berikut ini merupakan penjelasan kombinasi parameter yang digunakan pada 15 skenario uji coba.

- Parameter wintime: merupakan kombinasi panjang window dalam detik pada sebuah file audio yang akan diproses melalui ekstraksi fitur MFCC. Kombinasi nilai yang digunakan pada panjang window ini adalah 0,02 sampai 0,08 dengan kenaikan 0,02 pada setiap iterasi percobaan.

- Parameter Proporsi Data Latih dan Data Uji: merupakan kombinasi persentase data uji dan data latih pada masingmasing kelas yang terdiri dari $70 \%$ data latih $30 \%$ data uji hingga 90\% data latih dan 10\% data uji dengan kenaikan 5\% data latih dan penurunan $5 \%$ data uji pada setiap iterasi percobaan.

- Parameter Normalisasi Hasil Ekstraksi Fitur: merupakan kombinasi pemakaian metode normalisasi pada hasil ekstraksi fitur MFCC. Kombinasi metode normalisasi yang digunakan adalah Decimal Normalization, Min-Max Normalization, dan Standard Deviation Normalization pada setiap iterasi percobaan.

- Parameter Nilai k pada K-nearest Neighbor: merupakan kombinasi penggunaan nilai $k$ pada $K$-nearest Neighbor. Nilai yang digunakan ialah 1 sampai 5 dengan kenaikan 1 pada setiap iterasi percobaan.

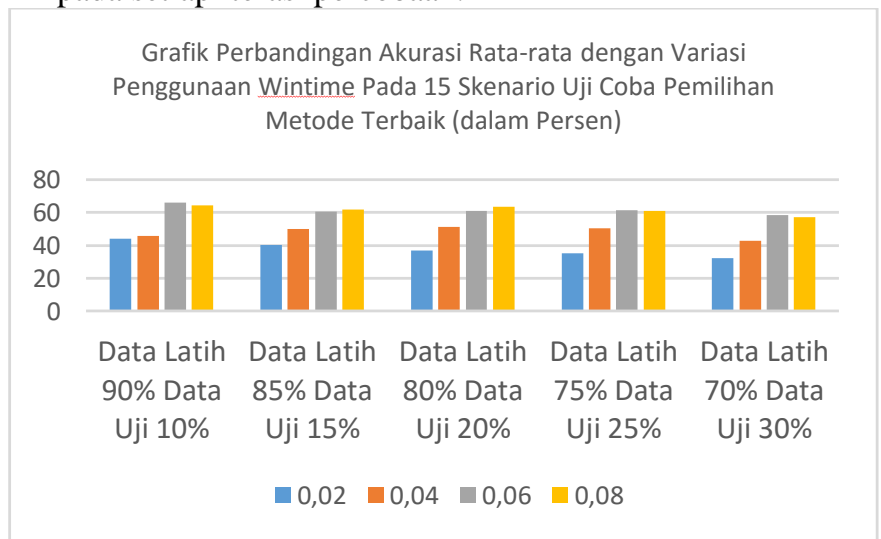

Gambar 3 Akurasi Rata-rata Penggunaan Kombinasi wintime pada 15 skenario percobaan 
Berdasarkan hasil uji coba pemilihan metode dari 15 skenario yang telah dilakukan, rata-rata akurasi terbaik sebesar $75,95 \%$ didapat ketika menggunakan wintime 0,08 dengan proporsi data latih $85 \%$ data uji $15 \%$, nilai $k=1$ pada $K$-nearest Neighbor, dan normalisasi hasil ekstraksi fitur dengan Standard Deviation Normalization. Dari 15 skenario uji coba tersebut, parameter wintime merupakan parameter yang paling berpengaruh terhadap akurasi klasifikasi. Semakin lama durasi dari audio yang akan diproses dengan ekstraksi fitur MFCC, maka penentuan wintime harus semakin besar agar fitur yang didapat semakin baik. Perbandingan akurasi penggunaan durasi wintime dapat dilihat pada Gambar 3.

\section{Uji Coba dengan Data Latih Seimbang pada Tiap Kelas}

Pengujian dilakukan dengan menggunakan parameter wintime sebesar 0,08 detik, K-nearest Neighbor dengan $k=1$ sampai $k=5$, normalisasi hasil ekstraksi fitur dengan Standard Deviation Normalization, dan data latih seimbang pada tiap kelas dilakukan untuk menganalisis kecenderungan salah deteksi dari jenis tangis satu ke jenis tangis lainnya. Data latih pada masing-masing kelas jenis tangis bayi akan diatur sebanyak 19, kemudian sisa data yang lain akan digunakan sebagai data uji. Akurasi hasil uji coba dengan data latih seimbang dapat dilihat pada Tabel 2 .

Berdasarkan uji coba dengan data latih seimbang, akurasi rata-rata terbaik yang didapat untuk mengklasifikasikan empat jenis tangis bayi sebesar $64,53 \%$ ketika nilai $k=1$ pada $K$ nearest Neighbor. Dari hasil uji dengan K-nearest Neighbor $k=1$, masing-masing suara tangis bayi ada yang dominan salah dideteksi sebagai jenis tangis lain. Kesalahan deteksi suara tangis "Eairh/Eh"dominan pada tangis "Owh", suara tangis "Heh" ada satu file yang salah dideteksi sebagai tangis "Eairh/Eh", suara tangis "Neh" dideteksi sebagai tangis "Eairh/Eh" dan "Heh", dan suara tangis "Owh" dominan salah dideteksi sebagai tangis "Neh".

Secara garis besar, jika dibandingkan dengan pembagian proporsi data latih berdasarkan persentase data dari tiap jenis bayi, akurasi yang dihasilkan jauh lebih baik karena data latih dari tiap jenis tangis bayi yang digunakan jauh lebih banyak.

Tabel 2

Perbedaan Hasil Klasifikasi KNN dengan Variasi Nilai $k$ pada Data Latih Seimbang

\begin{tabular}{cccccc}
\hline \hline Jenis & \multicolumn{5}{c}{ Klasifikasi KNN } \\
Tangis & $\mathbf{k = 1}$ & $\mathbf{k = 2}$ & $\mathbf{k = 3}$ & $\mathbf{k = 4}$ & $\mathbf{k = 5}$ \\
\hline Eairh/Eh & $51,85 \%$ & $70,37 \%$ & $55,56 \%$ & $51,85 \%$ & $55,56 \%$ \\
Heh & $75,00 \%$ & $75,00 \%$ & $100,00 \%$ & $100,00 \%$ & $75,00 \%$ \\
Neh & $75,00 \%$ & $50,00 \%$ & $56,25 \%$ & $62,50 \%$ & $56,25 \%$ \\
Owh & $56,25 \%$ & $31,25 \%$ & $43,75 \%$ & $37,50 \%$ & $37,50 \%$ \\
Akurasi & $\mathbf{6 4 , 5 3 \%}$ & $56,66 \%$ & $63,89 \%$ & $62,96 \%$ & $56,08 \%$ \\
rata-rata & & & & & \\
\hline \hline
\end{tabular}

D. Uji Coba dengan Metode Klasifikasi Lain

Tabel 3

Perbandingan Akurasi Metode Klasifikasi

\begin{tabular}{|c|c|c|c|c|}
\hline \multirow[b]{2}{*}{ Jenis Tangis } & \multicolumn{4}{|c|}{ Metode Klasifikasi } \\
\hline & KNN & $\begin{array}{l}\text { Naive } \\
\text { Bayes }\end{array}$ & $\begin{array}{c}\text { Neural } \\
\text { Network }\end{array}$ & SVM \\
\hline Eairh/Eh & $57,14 \%$ & $28,57 \%$ & $42,86 \%$ & $42,86 \%$ \\
\hline Heh & $66,67 \%$ & $100,00 \%$ & $100,00 \%$ & $66,67 \%$ \\
\hline Neh & $80,00 \%$ & $20,00 \%$ & $40,00 \%$ & $60,00 \%$ \\
\hline Owh & $100,00 \%$ & $80,00 \%$ & $80,00 \%$ & $100,00 \%$ \\
\hline Rata-Rata Akurasi & $75,95 \%$ & $57,14 \%$ & $65,71 \%$ & $67,38 \%$ \\
\hline
\end{tabular}

Uji coba dilakukan dengan menggunakan metode klasifikasi selain $K$-nearest Neighbor dengan $k=1$ untuk mengetahui perbandingan akurasi dari metode lain. Metode klasifikasi yang akan dibandingkan ialah Naive Bayes, Support Vector Machine, dan Neural Network. Pada klasifikasi Support Vector Machine, dengan metode One-againts-one, kernel yang digunakan ialah polynomial dan tidak menggunakan cross validation. Pada metode klasifikasi Neural Network, jumlah hidden layer yang digunakan sebanyak dua dengan 7 dan 5 node pada masingmasing layer, fungsi aktivasi yang digunakan ialah fungsi logistik, algoritma training yang digunakan ialah resilient backpropagation dengan weight backtracking, dan koefisien learning rate yang digunakan sebesar 0,02 . Proporsi data latih dan data uji yang digunakan pada tiga metode pembanding ialah $85 \%$ data latih dan $15 \%$ data uji dari tiap kelas. Nilai wintime yang digunakan pada ekstraksi fitur MFCC dari package tuneR sebesar 0,08 detik. Normalisasi hasil ekstraksi fitur yang digunakan ialah Standard Deviation Normalization.

Berdasarkan skenario uji coba perbandaingan tiga metode klasifikasi selain $K$-nearest Neighbor dengan $k=1$ pada tiap jenis tangis bayi, rata-rata akurasi klasifikasi terbaik sebesar 75,95\% didapat ketika menggunakan metode klasifikasi $K$ nearest Neighbor dengan $k=1$. Perbandingan akurasi tiap metode klasifikasi dapat dilihat pada Tabel 3. Perbedaan akurasi hasil klasifikasi ini wajar karena setiap metode memiliki kelebihan maupun kekurangan masing-masing dalam menangani data yang akan diklasifikasi

\section{E. Uji Coba Aplikasi Pendeteksi Suara Tangisan Bayi}

Uji coba aplikasi dilakukan untuk menguji apakah aplikasi mampu berjalan dengan baik dalam melakukan klasifikasi suara tangis bayi. Uji coba aplikasi dilakukan dengan menerapkan parameter berikut ini:

- $\quad$ wintime $=0,08$.

- data latih $85 \%$ dari setiap kelas jenis tangis bayi.

- nilai $k=1$ pada $K$-nearest Neighbor.

- normalisasi hasil ekstraksi fitur dengan Standard Deviation Normalization.

Sebanyak 139 audio tangis bayi diunggah ke aplikasi penerjemah tangis bayi secara satu per satu. Akurasi per kelas dan akurasi rata-rata pada uji coba aplikasi dapat dilihat pada Tabel 4.

Berdasarkan skenario uji coba aplikasi pendeteksi suara tangis bayi yang dilakukan, akurasi tiap kelas jenis tangis bayi dan akurasi rata-rata aplikasi sangat baik. Hasil akurasi yang tinggi pada aplikasi tersebut dapat dicapai karena $85 \%$ data latih pada tiap kelas jenis tangis bayi yang digunakan pada aplikasi pendeteksi suara tangis bayi juga digunakan sebagai data uji. Aplikasi dapat dikunjungi pada link di bawah ini: https://liemwellys.shinyapps.io/Aplikasi_Penerjemah_Tangis Bayil.

Tabel 4

Hasil Uji Coba Aplikasi Pendeteksi Suara Tangis Bayi

\begin{tabular}{lllll}
\hline \hline Eairh/Eh & Heh & Neh & Owh & Akurasi Rata-Rata \\
\hline $93,48 \%$ & $95,65 \%$ & $97,14 \%$ & $100,00 \%$ & $96,57 \%$ \\
\hline \hline
\end{tabular}

\section{KESIMPULAN}

- Parameter wintime pada proses ekstraksi fitur MFCC dari package tuneR ditentukan berdasarkan panjangnya durasi 
audio. Semakin panjang durasi audio yang akan diproses melalui ekstraksi fitur, maka nilai wintime harus semakin besar.

- Rata-rata akurasi terbaik sebesar $79,95 \%$ pada klasifikasi $K$-nearest Neighbor dengan $k=1$ didapat ketika proporsi data latih $85 \%$ data uji $15 \%$ dan proses ekstraksi fitur MFCC dengan durasi wintime 0,08 detik yang dinormalisasi dengan Standard Deviation Normalization.

- Hasil klasifikasi dengan pembagian proporsi data latih berdasarkan persentase data dari masing-masing jenis tangis bayi menghasilkan akurasi yang lebih baik jika dibandingkan dengan klasifikasi yang menggunakan data latih seimbang dari tiap jenis tangis bayi.

- Aplikasi dapat mendeteksi masing-masing jenis tangis bayi dengan akurasi rata-rata 96,57\%. Hasil ini diperoleh karena $85 \%$ dari data uji pada tiap kelas digunakan sebagai data latih dalam aplikasi.

\section{DAFTAR PUSTAKA}

[1] K. Srijiranon dan N. Eiamkanitchat, "Application of Neuro-Fuzy Approaches to Recognition and Classification of Infant Cry," dalam TENCON 2014 - 2014 IEEE Region 10 Conference, Bangkok, 2014.

[2] M. D. Renanti, "Identifikasi Arti Tangis Bayi Versi Dunstan Baby Language Menggunakan Jarak Terpendek dari Jarak Mahalanobis," Jurnal Sains Terapan, vol. 3, no. 5, pp. 39-44, 2013.

[3] M. Hariharan, R. Sindhu dan S. Yaacob, "Normal and Hypoacoustic Infant Cry Signal Classification Using Time-Frequency Analysis and General Regression Neural Network," Computer Methods and Programs in Biomedcine, vol. 108, no. 2, pp. 559-569, November 2012.

[4] P. Dunstan, “Open Up and Discover Your Baby's Language,” 2006. [Online]. Available: http://www.babytaal.nl/media/PDF/ComprehensiveBooklet(2).pdf. [Diakses 2 Juli 2016].

[5] L. Muda, M. Begam dan I. E., "Voice Recognition Algorithms using Mel Frequency Cepstral Coefficient (MFCC) and Dynamic Time Warping (DTW) Techniques," JOURNAL OF COMPUTING, vol. 2, no. 3, pp. 138-143, 2010.

[6] D. Putra dan A. Resmawan, "Verifikasi Biometrika Suara Menggunakan Metode MFCC dan DTW," Lontar Komputer, vol. 2, pp. 8-21, 2011.

[7] R. Jang, “12-2 MFCC," [Online]. Available: http://mirlab.org/jang/books/audiosignalprocessing/speechFeatureMfc c.asp?title=12-2\%20MFCC. [Diakses 3 Juli 2016].

[8] Kalid, "An Interactive Guide To The Fourier Transform," [Online]. Available: http://betterexplained.com/articles/an-interactive-guide-tothe-fourier-transform/. [Diakses 5 Juli 2016].

[9] Z.-H. Tan dan B. Lindberg, "Use of Cepstral Liftering for MFCC Variance Normalization," dalam Automatic Speech Recognition on Mobile Devices and over Communication Networks, Springer Science \& Business Media, 2008, pp. 148-150.

[10] "Pengertian, kekurangan dan kelebihan K-NN," 2012. [Online]. Available: http://cgeduntuksemua.blogspot.com/2012/03/pengertiankelebihan-dan-kekurangan-k.html. [Diakses 15 Januari 2016]. 